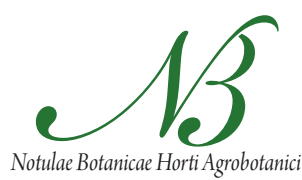

Cluj-Napoca

\title{
RAPD and ISSR Methods Used for Fingerprinting Selected, Closely Related Cultivars of Aronia melanocarpa
}

\author{
Miłosz SMOLIK*, Ireneusz OCHMIAN, Beata SMOLIK
}

${ }^{1}$ West Pomeranian University of Technology in Szczecin, Stowackiego 17, 71-434 Szczecin, Poland; msmolik@zut.edu.pl (*corresponding author)

\begin{abstract}
RAPD (Random Amplified Polymorphic DNA) and ISSR (Inter Simple Sequence Repeats) markers were used to analyse the genetic diversity between six genotypes of Aronia melanocarpa ('Hugin', 'Nero,' 'N', 'Viking,' 'Galicjanka 1' and 'Galicjanka 2'), collected at the Department of Pomology at the West Pomeranian University of Technology in Szczecin, Poland. Analysis of 24 RAPD and 25 ISSR primers showed very low genetic diversity between the compared cultivars. Analysis of 214 RAPD loci and 184 ISSR loci revealed that the following five genotypes: 'Nero, 'N', 'Viking', 'Galicjanka 1' and 'Galicjanka 2' are characterized by a very small range of diversity in comparison to the substantially different cultivar 'Hugin'. For each genotype, specific products were generated, including 36 products generated in RAPD reactions for cultivar 'Hugin' only, and 20 for the other five genotypes altogether. Specific products were amplified also with the use of the ISSR technique. Thirty-nine ISSR products were generated for the cultivar 'Hugin' only, and 8 for the other five genotypes altogether. Results of the research indicate a very small range of diversity between the Aronia accessions. Analysis of mutual genotypic relationships between the compared accessions was carried out with the use of the Mantel test and found a significant correlation $(\mathrm{r}(\mathrm{AB})=0.531)$ between similarity matrices calculated on the basis of results obtained with the use of the RAPD and ISSR techniques.
\end{abstract}

Keywords: Aronia sp., genotypes, RAPD, ISSR, high genetic similarity, molecular markers, fingerprint

\section{Introduction}

The genus Aronia is a diploid $(2 \mathrm{n}=34)$ from the family Rosaceae (Lehmann 1990). It originated in Eastern North America and Eastern Canada. In the beginning of the $20^{\text {th }}$ century the genus was introduced in Germany and Eastern Europe, including the former Soviet Union where the species, propagated from the seeds from German collections, acquired the status of a cultivar and since the 1940s has been intensively grown (Strigl et al., 1995).

The genus Aronia includes two very economically important species: Aronia melanocarpa (Michx.) Elliot (black chokeberry) and Aronia arbutifolia L. Elliot (red chokeberry) (Hardin, 1973). There have been some reports also of the third species, A. prunifolia (Marsh.) Rehder. According to Hardin (1973), this species is probably a hybrid between the other two species, and he suggested including A. prunifolia (with purple black berries) into black chokeberry since they are extremely difficult to distinguish.

Aronia melanocarpa, because of its properties widely used in the food industry (for example as a natural food colouring-Kulling and Rawel, 2008; Oszmiański and Sapis, 1988; Plocharski and Zbroszczyk, 1989; Strigl et al., 1995) and pharmaceutical industry, is one of the most valuable species of farm plants. Its fruit has strong antioxidant (Hukkanen et al., 2006; Kahkonen et al., 2001), anti-inflammatory (Borissova and Valcheva, 1994), anti- bacterial, antiviral and antihemorrhagic activity (Vachleva-Kuzmanova et al., 2007), strengthens blood vessel walls (Simeonov et al., 2002), lowers blood pressure and has anti-mutagenic effect (Gąsiorowski et al., 1997).

Chokeberry fruit is rich in biologically active compounds, such as pectins (Tanaka and Tanaka, 2001), flavonoids (Benvenuti et al., 2004), polyphenols (Benvenuti et al., 2004; Richter, 1988; Skupień and Oszmiański, 2007), anthocyanins (Benvenuti et al., 2004; Lüdders and Foltan, 1997; Oszmianski and Sapis, 1988), organic acids (Ara, 2002), and many vitamins, including E, B2, B6, B9, $\mathrm{PP}$ and carotene (provitamin A), scarce in any other fruit (Ara, 2002; Skupień and Oszmianski, 2007; Tanaka and Tanaka, 2001).

As a result of selection work, especially within the species $A$. melanocarpa and the hybrid $A$. prunifolia, a range of cultivars was obtained, grown for the desired dark colour of the fruit, its nutritional values and for shrubs of ornamental value.

At present, the cultivars of the greatest economic significance in chokeberry growing are 'Nero' (the Czech Rebublic) and 'Rubina' (hybrid from Russian and Finnish components), 'Viking,' 'Hakkija, 'Ahonnen', 'Kurkumäcki' (Finland), 'Hugin' (Sweden), 'Fertödl' (Hungary), 'Aron' and 'Serina' (Denmark) or 'Galicjanka' (Poland) (Jeppsson, 2000; Strigl et al., 1995). 
Starting material for breeding of these listed above cultivars included, among others, Russian breeding material, which, as it has been already mentioned, is characterized by limited diversity (Kask, 1987). In Russia in the 1940s, chokeberry fruit plantations were established from plants propagated from seeds (Kask, 1987). The plantations were a monoculture and since the range of diversity within the genus is limited, generally such a plantation was moderately genetically similar, which had no influence on differences in crop characterization (Jeppsson, 1999; Skvortsov and Maitulina, 1982).

However, it should be noted that the genotypes (recombinants) taken as a starting material from Russian collections were often gene sources for newly-bred cultivars in breeding programmes implemented in Sweden, Finland or Poland. These actions could have resulted in the genetic unification of its new cultivars, i.e. 'Nero, 'Viking' or 'Galicjanka', and, by extension, in reaching some level of diversity of traits concerning biological properties of Aronia that would be difficult to exceed.

This progress is possible only in the situation when genetically different components characterized by various biological properties are selected for crossings in breeding programmes. In this type of work, wild genotypes of Aronia genus and interspecific hybrids are especially important. Breeding progress will not be effective when closely related genotypes are used in breeding programmes as a starting material.

Hence, the aim of the present study was to determine the range of diversity, fingerprints and mutual phylogenetic relationships between the examined Aronia genotypes, and to assess the usefulness of the ISSR and RAPD techniques for this task, corroborated with the analysis of correlations between genetic relationship matrices among the examined Aronia cultivars, calculated separately for each technique on the basis of respective genetic profiles.

\section{Material and methods}

Six genotypes of black chokeberry (Aronia melanocar$p a$ (Michx.) Elliot.): including 'Hugin', 'Nero, 'N', 'Viking', 'Galicjanka 1' and 'Galicjanka 2' from the collection of the Fruit Growing Research Station in Rajkowo of the West Pomeranian University of Technology in Szczecin were used in this study. The cultivar 'Hugin' was obtained from the Kordes-Jungpflanzen collection (Germany), 'Nero' and 'Viking' were obtained from the Baumschule Horstmann in Hohenaspe (Germany), and the genotype ' $\mathrm{N}$ '(unknown, has been in collection for over twenty years. There is no information about the origin of the last genotype). The cultivar 'Galicjanka' was selected and vegetatively propagated in the Research Centre of the Institute of Pomology and Floriculture in Albigowa near tańcut (Poland). The collection of the Departament of Pomology includes plants of this cultivar from two different places, named 'Galicjanka 1', obtained from the Licensed Nursery
(Lublin, Poland), and 'Galicjanka 2', obtained from the Institute of Pomology and Floriculture in Skierniewice (Poland).

\section{DNA preparation}

DNA was prepared from young leaves of six Aronia shrubs with DNeasy Plant Mini Kit (Qiagen-Germany). Contaminating RNA was removed by digestion with RNase A $\left(10 \mathrm{mg} \cdot \mathrm{ml}^{-1}\right)$.

\section{RAPD amplification}

PCR amplifications were performed with a set of 24 random primers-part of Operon kits (Operon Technologies-USA). Reaction mixture $(25 \mu \mathrm{l})$ contained $10 \times$ PCR buffer with $\left(\mathrm{NH}_{4}\right)_{2} \mathrm{SO}_{4}(750 \mathrm{mM}$ Tris- $\mathrm{HCl}$ $\mathrm{pH} 8.8,200 \mathrm{mM}\left(\mathrm{NH}_{4}\right)_{2} \mathrm{SO}_{4}, 0.1 \%$ Tween 20$), 0.2 \mathrm{mM}$ of dNTPs, $2 \mathrm{mM} \mathrm{MgCl}$, $0.25 \mu \mathrm{M}$ of primer, $1 \mathrm{u}$ of Taq DNA polymerase enzyme (Fermentas MBI) and 30-40 ng of template DNA. The reactions were performed in a Mastercycler 5333 (Eppendorf). The programme of thermal cycling was as follows: initial activation step at $95^{\circ} \mathrm{C}$ for $15 \mathrm{~min}$, followed by 40 cycles for $1 \mathrm{~min}$ at $94^{\circ} \mathrm{C}, 1 \mathrm{~min}$ at $36^{\circ} \mathrm{C}$ and $2 \mathrm{~min}$ at $72^{\circ} \mathrm{C}$, with the final extension step at $72^{\circ} \mathrm{C}$ for $10 \mathrm{~min}$. The amplification reaction was conducted by the final extension at $72^{\circ} \mathrm{C}$ for $5 \mathrm{~min}$.

\section{ISSR amplification}

PCR amplifications were performed with a set of 40 random primers from a part of UBC sets (UBCUniversity of British Columbia primer sets). The reactions were performed in a Mastercycler 5333 (Eppendorf). Reaction mixture $(25 \mu \mathrm{l})$ contained $10 \times$ PCR buffer with $\left(\mathrm{NH}_{4}\right)_{2} \mathrm{SO}_{4}(750 \mathrm{mM}$ Tris- $\mathrm{HCl}$ $\mathrm{pH} 8.8,200 \mathrm{mM}\left(\mathrm{NH}_{4}\right)_{2} \mathrm{SO}_{4}, 0.1 \%$ Tween 20$), 0.2 \mathrm{mM}$ of dNTPs, $2 \mathrm{mM} \mathrm{MgCl} 2,0.20 \mu \mathrm{M}$ of primer, $1 \mathrm{u}$ of Taq DNA polymerase enzyme (Fermentas MBI) and $50 \mathrm{ng}$ of template DNA. Forty ISSR primers were tested during the initial screening. The primers were 17 - to 18 -mers based on various di-,-tri-, -tetra- and pentanucleotide repeats. They were anchored at the 3' end. The twenty five primers that gave the most informative patterns were used to characterize the diversity of the Aronia cultivars (Tab. 1). The programme of thermal cycling was as follows: $94^{\circ} \mathrm{C}$ for $7 \mathrm{~min}, 40$ cycles for $30 \mathrm{~s}$ at $94^{\circ} \mathrm{C}, 50 \mathrm{~s}$ at annealing temperature, $2 \mathrm{~min}$ at $72^{\circ} \mathrm{C}$, and $7 \mathrm{~min}$ at $72^{\circ} \mathrm{C}$ for the final extension.

\section{Electrophoresis}

Amplification products were visualized on 2\% agarose gel (Basica LE-Prona) in TBE buffer stained with ethidium bromide. As a size marker, an O'RangeRuler 200 bp DNA ladder (Fermentas MBI) was run in each gel.

\section{Data analysis}

The molecular size of each fragment was estimated using GelCapture-(MiniBis Pro-Bio Imaging Systems-Israel). 
278

For each RAPD and ISSR primer amplification products were scored as 1 (present) or 0 (absent) for a cultivar and similarity index matrices were generated on the basis of a number of shared fragments. Similarity index $S=2 \mathrm{Nab} /$ $(\mathrm{Na}+\mathrm{Nb})$, where $\mathrm{Na}$ and $\mathrm{Nb}$ represent the total number of bands present in lanes a and $\mathrm{b}$, respectively, and $\mathrm{Nab}$ is the number of bands shared by both lanes (Nei and Li, 1979). The genetic similarity between cultivars were evaluated by calculating the Nei and $\mathrm{Li}$ (1979) similarity coefficient for pairwise comparisons based on the proportion of shared bands produced by the primers. Similarity matrices were generated using the PhylTool software (Buntjer, 2001) and were compared by calculating the product-moment correlation (Pearson) between matrices and the Mantel (Daniel's) test statistics (Z) of significance (Manly, 1997) using the XLSTAT software. The relationship between the 6 cultivars were shown in the form of a dendrogram. The strength of the internal branches from the resulting tree were tested by the TREECON bootstrap analysis application using 2,000 pseudoreplications (Felsenstein, 1985; Van der Peer and de Wachter, 1994).

\section{Results}

The genetic research conducted with the use of two DNA analysis techniques (RAPD and ISSR) revealed that the range of diversity within the six compared genotypes of black chokeberry (Aronia melanocarpa) is small. The analysis of genetic profiles of the compared genotypes showed that only cultivar 'Hugin' differs significantly from the others. The accessions: 'Nero,' 'N', 'Viking,' 'Galicjanka 1 ' and 'Galicjanka 2' generally were quite similar, when the genetic profiles were compared. The only small range of diversity was found for several amplified RAPD and ISSR loci as the presence of polymorphic or genotype-specific products of RAPD or ISSR reactions.

\section{RAPD-Random Amplified Polymorphic DNA}

A total of 214 loci (845 amplicons) were amplified for the examined 6 Aronia genotypes, of which $81(38 \%)$ RAPD loci were monomorphic, 69 (32\%)-polymorphic and 64 (30\%)-genotype-specific (Tab. 1). On average, in a reaction with one primer used in the study, 9 RAPD loci were amplified, of which 3 were monomorphic, 3 polymorphic and 3 genotype-specific. The length of the amplified RAPD products ranged from 2810 (OPA_01) to 270 bp (OPJ_01), and the largest number of RAPD loci (18) was amplified in reactions with primer OPA_01, while the smallest number of loci (4) was amplified with primer OPM_03 (Tab. 1).

\section{Monomorphic loci}

The nature of the amplified RAPD fragments common to the six examined accessions is presented in Tab. 1 and Fig. 1.

Thirty-eight percent of all amplified loci were products identical in all the six examined Aronia genotypes, and thus in the examined genotypes the largest number of loci of this type were amplified in reactions with all the primers OPA_03 (8) and OPW_09 (6), and the smallest number of loci-two monomorphic loci, with each of primers: OPM_03, OPM_05 and OPW_01. One locus of this type was amplified with primer OPJ_13, and no monomorphic loci were amplified in reactions with prim-

Tab. 1. Characteristics of generated RAPD and ISSR products for six genotypes of Aronia melanocarpa

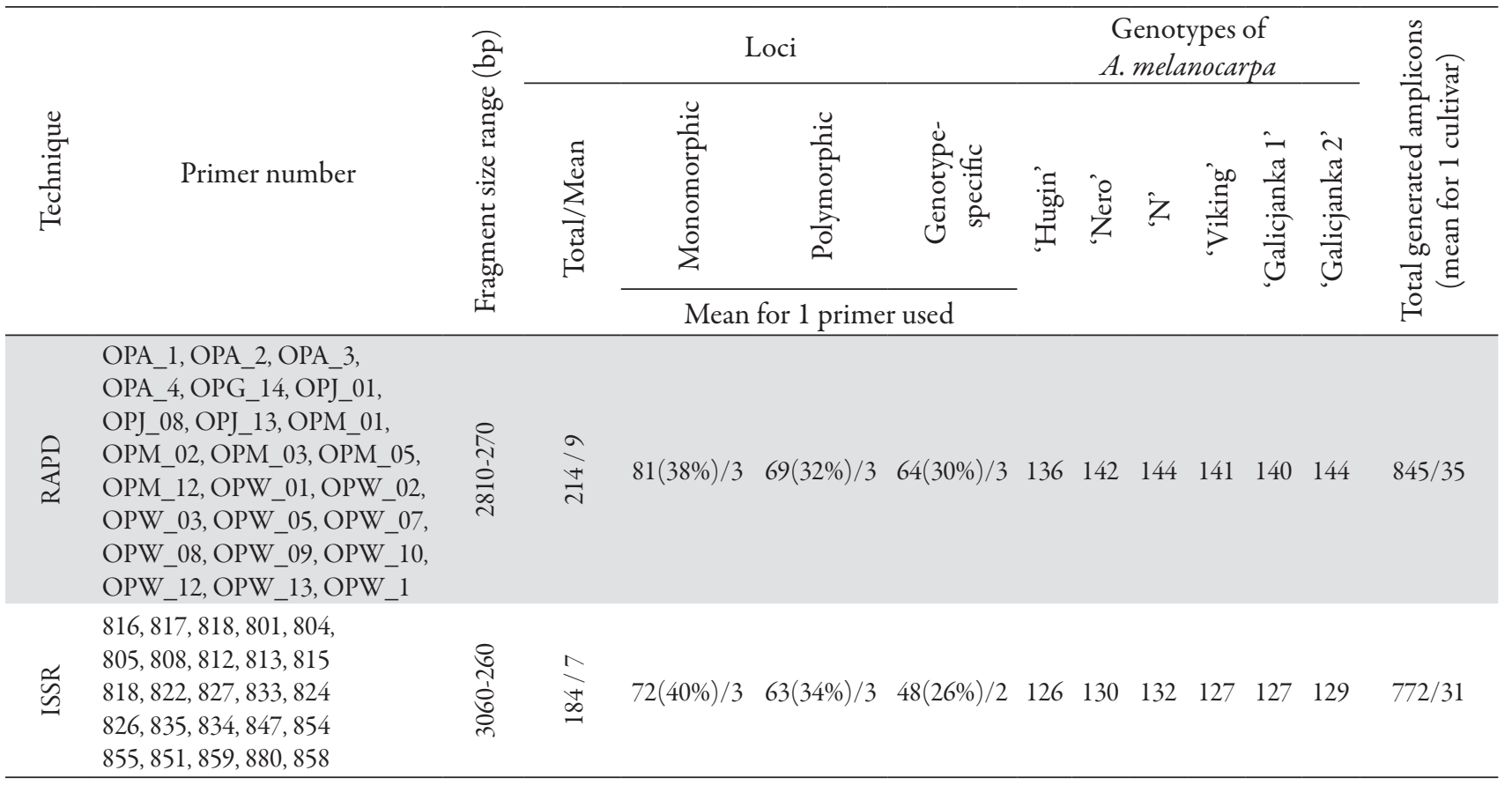



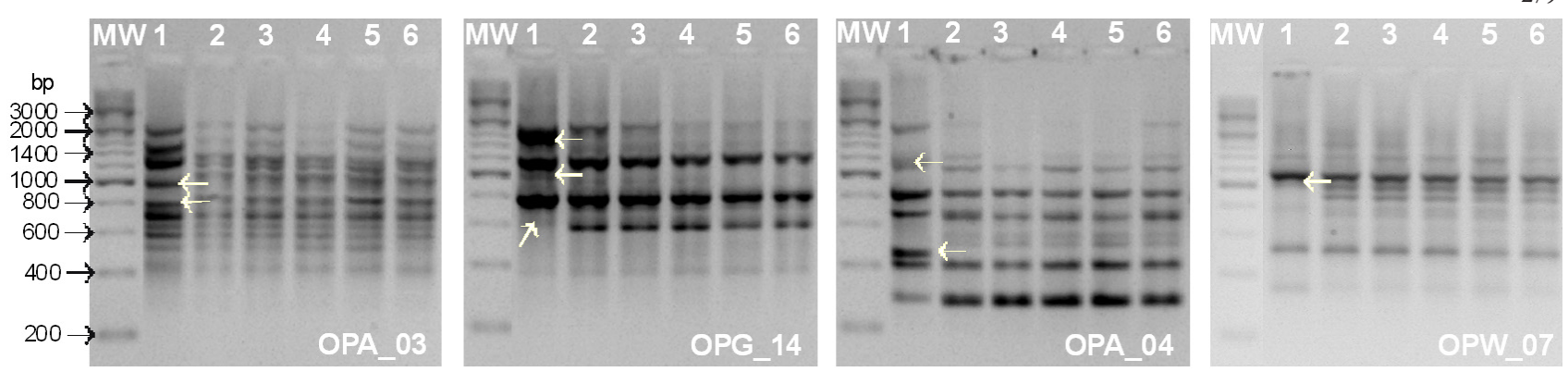

MW-Molecular Weight-O’RangeRuler 200 bp DNA Ladder, 1-'Hugin', 2 -'Nero', 3-'N', 4-'Viking', 5-'Galicjanka 1', 6-'Galicjanka 2' Fig. 1. RAPD fingerprints of six genotypes of Aronia melanocarpa. Polymorphic amplicons marked with white arrows are cultivarspecific

ers OPA_01 and OPJ_08. The analysis of RAPD genetic profiles of the genotypes 'Nero, 'N', 'Viking', 'Galicjanka 1 ' and 'Galicjanka 2' revealed that the genotypes are very similar (Fig. 1).

\section{Polymorphic loci}

In the present experiment, 69 (32\%) RAPD loci were defined as polymorphic in the examined Aronia genotypes. It was found that the cultivar 'Hugin' clearly differed from the other five genotypes (Fig. 1), hence some RAPD loci, with which that cultivar was different from the other accessions, were polymorphic in almost every examined RAPD profile. Thus, the greatest number of loci of this type, respectively 9 and 7 , was amplified in reactions with primers OPJ_08 and OPA_01, one locus respectively with each of primers: OPM_03, OPW_08 and OPW_12. No polymorphic loci were amplified in reactions with primers OPA_02 and OPA_04 (Tab. 2).

\section{Genotype-specific loci}

About $30 \%$ of this type of loci was amplified in the present experiment, and their characterization is presented in Tab. 3. For each of the six examined Aronia genotypes, genotype-specific RAPD products (loci) were determined in the examined genetic profiles (Tab. 2, Fig. 1).

The largest number of this type of loci was found in genetic profiles of the cultivar 'Hugin' (Fig. 1); thus 36 genotype-specific RAPD loci were amplified for this cultivar in reactions with 17 RAPD primers (Tab. 2). The greatest number of loci, respectively 6 and 4, was generated in reactions with primers OPA_01, OPM_05 and OPM_12. One RAPD product was amplified with each of prim- ers: OPA_02, OPG_14, OPJ_08, OPJ_13, OPM_01, OPW_07, OPW_08, OPW_10 and OPW_12 (Ta $\bar{b} .2$, Fig. 1).

\section{ISSR-Inter Simple Sequence Repeat}

A set of 30 microsatellite primers, $16-18$ bp long, characterized by the different sequence of the 3 ' end, was used in ISSR reactions. In cyclical ISSR amplifications for the six Aronia genotypes, clear genetic profiles were obtained in reactions with 25 primers. Their detailed characterization is presented in Tab. 1. A total of 184 ISSR loci (772 amplicons) were amplified in the experiment, of which 72 (40\%) loci were monomorphic, 63 (34\%)-polymorphic and 48 (26\%)-genotype-specific (Tab. 1). On average, in a reaction with one ISSR primer, 7 ISSR loci were amplified for the examined Aronia accessions, including on average 3 monomorphic loci, 3 polymorphic loci and 2 genotypespecific loci. The longest ISSR products (3060 bp) were amplified in a reaction with primer 813 , and the shortest ones $(230 \mathrm{bp})$ with primer 858 .

\section{Monomorphic loci}

Analysis of ISSR profiles of the six Aronia genotypes (including the cultivar 'Hugin') as a complete experimental material enabled to identify for them 72 identical ISSR products. Their characterization is presented in detail in Tab. 1 and Fig. 2.

\section{Polymorphic loci}

Sixty-three (34\%) ISSR loci were defined as polymorphic. Similarly as in the RAPD technique, the cultivar 'Hugin' clearly differed from the other five accessions

Tab. 2. Genotype-specific RAPD products generated for six genotypes of $A$. melanocarpa

\begin{tabular}{|c|c|}
\hline Cultivars & Primers and cultivar-specific RAPD products \\
\hline 'Hugin' & 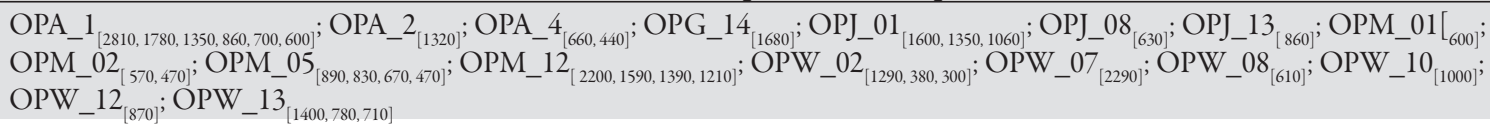 \\
\hline 'Nero’ & OPA_1 ${ }_{[1110]} ;$ OPW_02 $[1650] ;$ OPW_13 $3_{[1450]}$ \\
\hline 'N' & OPA_1 ${ }_{[2480,1845]} ;$ OPG_14 ${ }_{[1800]} ;$ OPW_01 ${ }_{[900]} ;$ OPW_1 $1_{[1150]}$ \\
\hline 'Viking' & OPA_1 ${ }_{[830]} ;$ OPJ_08 $8_{[1900,990]}, \mathrm{OPW} \_01_{[1910]}$ \\
\hline 'Galicjanka 1' & OPA_1 ${ }_{[1300]} ;$ OPW_01 \\
\hline 'Galicjanka 2’ & OPA_4 $4_{[1970]} ;$ OPJ_08 $8_{[400]} ;$ OPM_03 $3_{[600]} ;$ OPW_03 \\
\hline
\end{tabular}



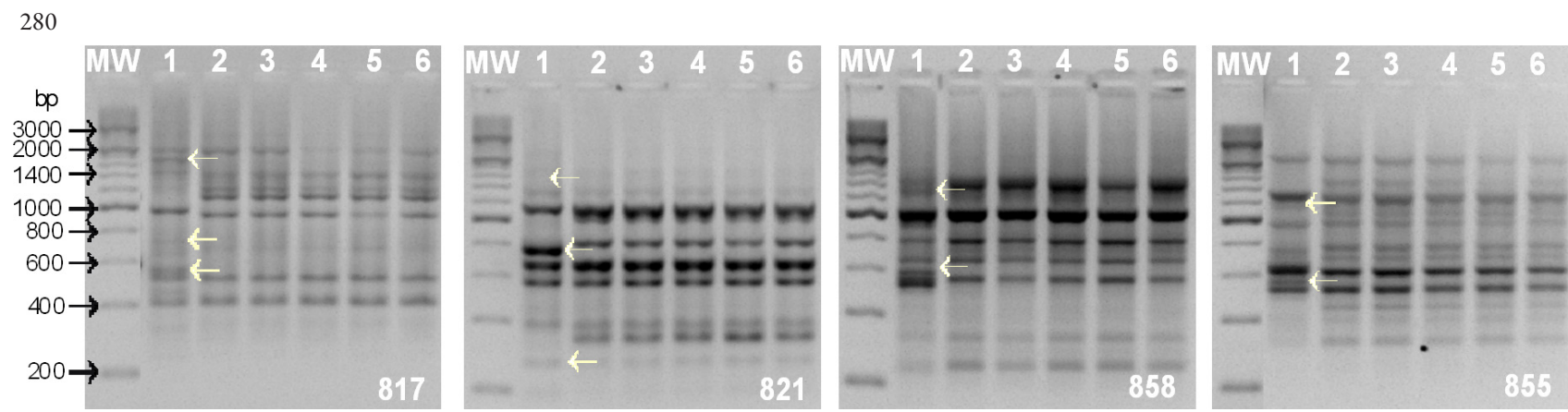

MW-Molecular Weight-O’RangeRuler 200 bp DNA Ladder, 1-'Hugin', 2-'Nero', 3-'N', 4-'Viking', 5-'Galicjanka 1', 6-'Galicjanka 2'

Fig. 2. ISSR fingerprints of six genotypes of Aronia melanocarpa. Polymorphic amplicons marked with white arrows are genotypespecific

Tab. 3. Genotype-specific ISSR products generated for six cultivars of $A$. melanocarpa

\begin{tabular}{|c|c|}
\hline Cultivars & Primers and cultivar-specific ISSR products \\
\hline 'Hugin' & 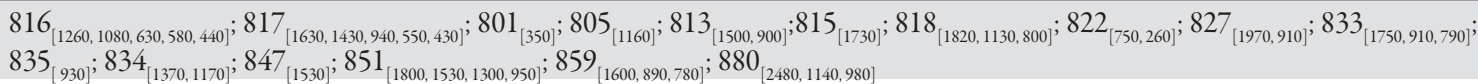 \\
\hline 'Nero' & $805_{[570]}$ \\
\hline 'N' & $847_{[1200]} ; 880_{[2610]}$ \\
\hline 'Viking' & $818_{[650]} ; 834_{[1200]}$ \\
\hline 'Galicjanka 1' & $815_{[2570]} ; 818_{[1670]}$ \\
\hline 'Galicjanka 2' & $818_{[1200]}$ \\
\hline
\end{tabular}

(Fig. 2). Taking into consideration the presence of ISSR products specific to the genotypes 'Nero', 'N', 'Viking', 'Galicjanka 1' and 'Galicjanka 2' in their genetic profiles, the pool of ISSR products defined in the experiment as polymorphic amounted to $34 \%$. The largest number of loci of this type (5) was amplified in reactions with each of primers respectively: $818,822,824$ and 833 , one locus respectively with each of primers: 815 and 835 (Tab. 1).
No polymorphic loci were amplified in reactions with the following primers: $804,808,854$ and 858.

\section{Genotype-specific loci}

In the experiment 48 genotype-specific loci were found in comparison to other Aronia genotypes (Tab. 1). It was possible to relate a unique ISSR product to each of the six examined Aronia accessions that distinguishes the ex-

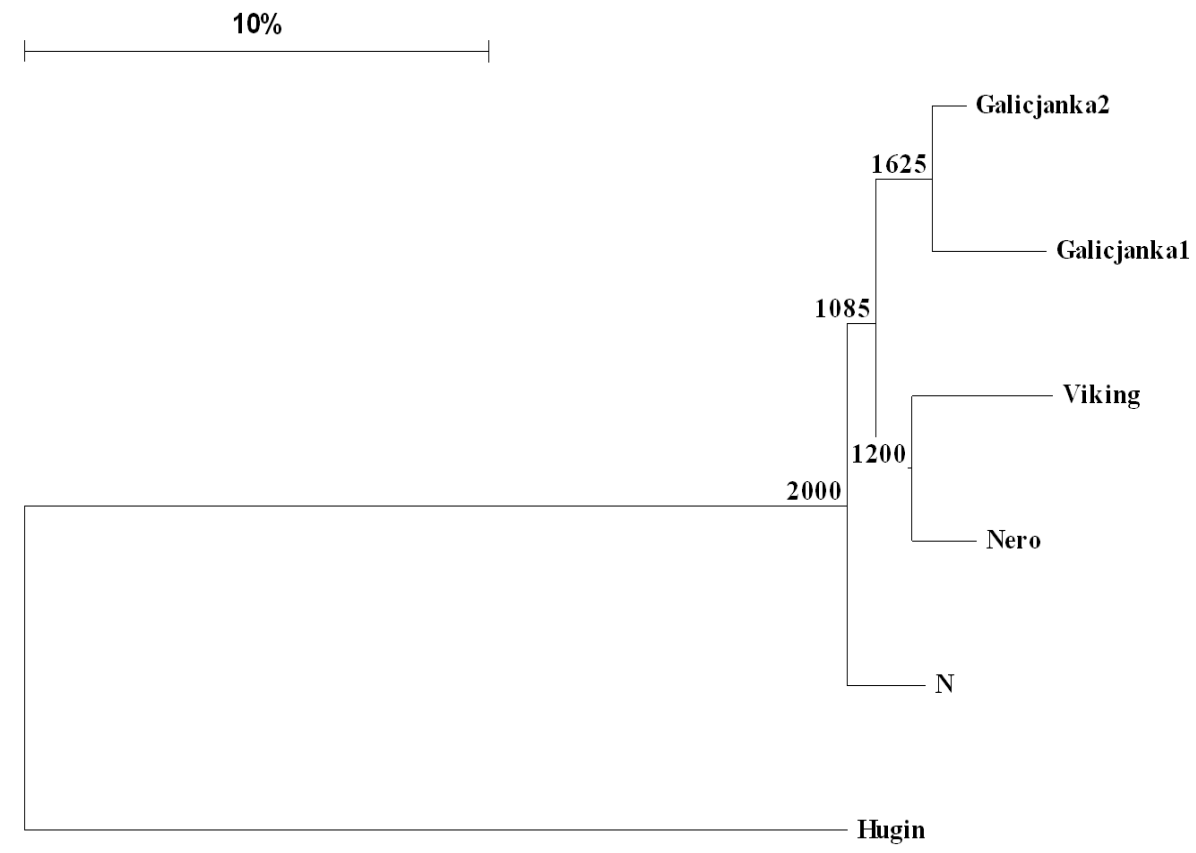

Fig. 3. Dendrogram of the Aronia's genotypes based on the similarity matrix developed for ISSR band profiles. Numbers near branches are bootstrap values 


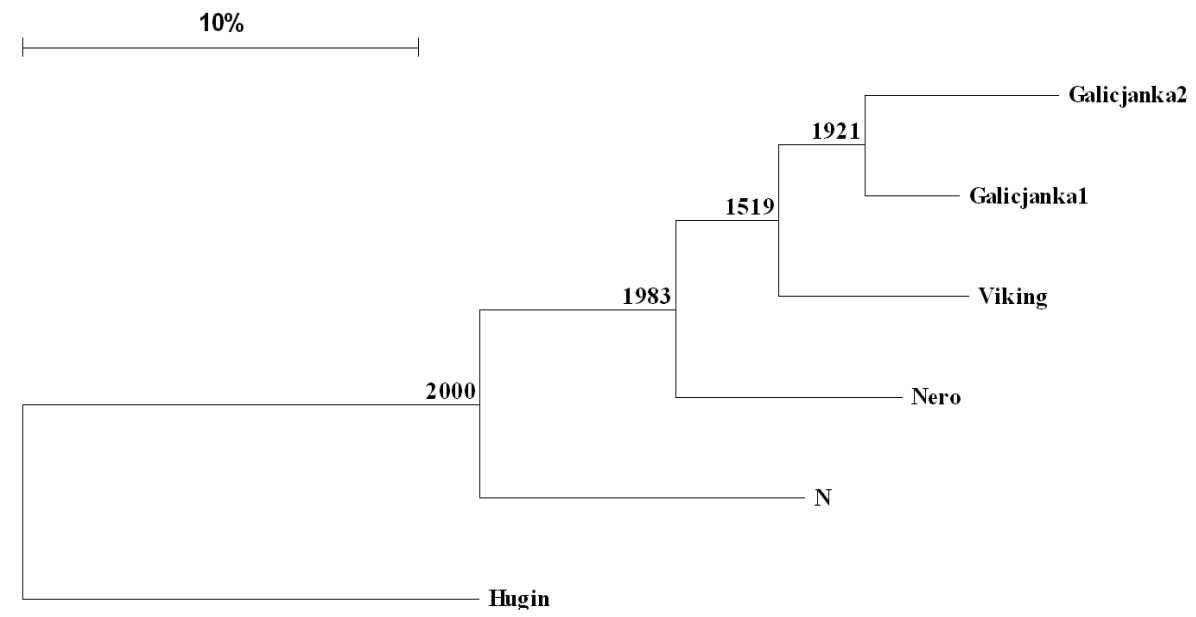

Fig. 4. Dendrogram of the Aronia's genotypes based on the similarity matrix developed for RAPD band profiles. Numbers near branches are bootstrap values

amined genotype from the others. The greatest number of products of this type was found in the genetic profiles of the cultivar 'Hugin' (16 ISSR primers-39 specific loci), and the smallest number (1 locus) in the profiles of each of the genotypes: 'Nero' and 'Galicjanka 2'. Two specific ISSR loci were observed for each of the genotypes: 'N', 'Viking' and 'Galicjanka 1' (Tab. 3).

Tab. 4. Genetic similarity among six genotypes of Aronia melanocarpa assessed through two molecular markers systems

\begin{tabular}{|c|c|c|c|c|c|c|c|}
\hline & \multirow[b]{2}{*}{$\begin{array}{l}\text { Similarity } \\
\text { matrix }\end{array}$} & \multicolumn{6}{|c|}{ RAPD } \\
\hline & & : & 㻤 & $\bar{Z}$ & 夏 & 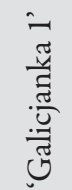 & 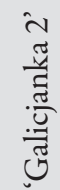 \\
\hline \multirow{6}{*}{ ISSR } & 'Hugin' & 1,00 & 0,67 & 0,70 & 0,68 & 0,65 & 0,64 \\
\hline & 'Nero' & 0,63 & 1,00 & 0,83 & 0,86 & 0,89 & 0,86 \\
\hline & 'N' & 0,64 & 0,96 & 1,00 & 0,82 & 0,79 & 0,77 \\
\hline & 'Viking' & 0,62 & 0,95 & 0,93 & 1,00 & 0,91 & 0,88 \\
\hline & 'Galicjanka l' & 0,77 & 0,75 & 0,74 & 0,73 & 1,00 & 0,93 \\
\hline & 'Galicjanka 2' & 0,63 & 0,95 & 0,95 & 0,95 & 0,73 & 1,00 \\
\hline
\end{tabular}

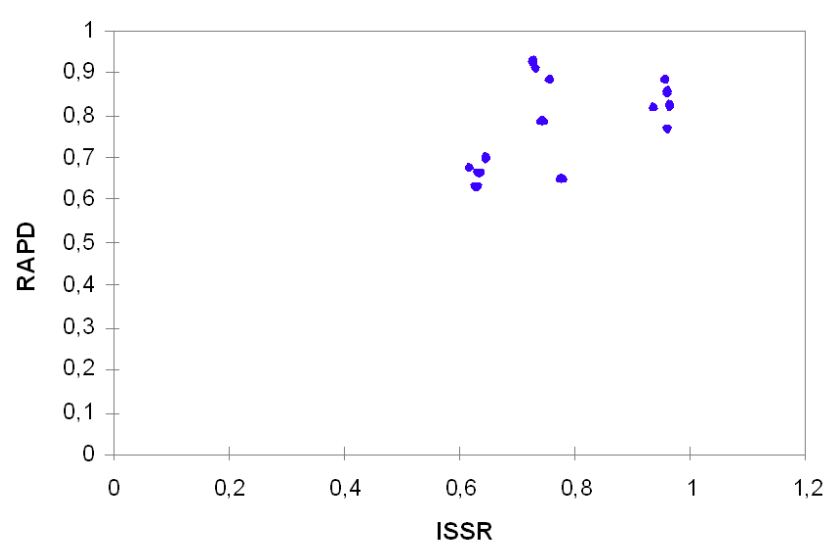

\section{Phylogenetic analysis}

On the basis of the genetic profiles obtained with the use of the RAPD and ISSR technique, respectively two dendrograms of phylogenetic similarity were generated for the six examined Aronia genotypes (Fig. 3 and 4).

The topology of the obtained phylogenetic trees in both techniques (RAPD and ISSR) similarly showed genetic relationships between the compared genotypes.

The RAPD analysis revealed that genetic similarity between the compared genotypes varied from 64 to $93 \%$ (Tab. 4). The genetically most similar genotypes included 'Galicjanka 1' and 'Galicjanka 2' (93\%), while the least similarity was found between the cultivar 'Hugin' and genotype 'Galicjanka 2' (64\%) and 'Hugin' and 'Galicjanka 1' (65\%) respectively (Tab. 4).

Analysis of the topology of the phylogenetic tree generated on the basis of ISSR profiles, rooted to the cultivar 'Hugin', distinctly different from the other genotypes, showed that genetic similarity between the examined genotypes varied from 62 to $96 \%$. The greatest similarity was found between the genotypes 'Nero' and ' $N$ ' (similarity of 96\%), and the least between 'Hugin' and 'Viking' (62\%).

Histogram (Mantel test)

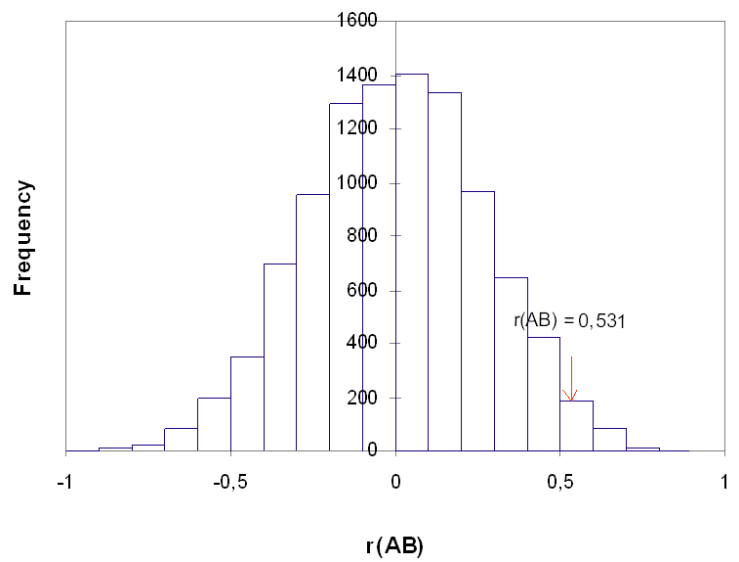

Fig. 5. The Mantel test correlation assessed for two similarity matrices (RAPD and ISSR) presented in graphically form 
282

Similarity between cultivar 'Hugin' and genotype 'Galicjanka 2' was 63\% (Tab. 4).

The topology of the generated trees was tested with bootstrap analysis of 2,000 pseudoreplicates. In both trees the branch support was distinct, and its values are given above each of the tested branches, respectively for each of the constructed trees.

The genetic similarity matrix data generated with the RAPD and ISSR methods were compared using the correlation coefficient, and the significance was determined using the Mantel test. In the present study correlation between the two similarity matrices was shown on a histogram and was highly significant $(\mathrm{r}(\mathrm{AB})=0.531$, $\mathrm{p}$-value $=0.044, p=0.05)$, indicating congruence between the compared molecular marker methods (Fig. 5).

\section{Discussion}

Since DNA markers are numerous, they may potentially cover the entire genome. They are not influenced by developmental stage or environment, which enables to select individuals already at the seedling stage, that is as soon as the plants are large enough to yield a sufficient amount of DNA. There are number of molecular techniques available for the characterization of DNA variation. For genetic diversity studies, the RAPD (Klein-Lankhorst et al., 1991; Lanham et al., 1995; Levi and Rowland, 1997; Moreno et al., 1995; Williams et al., 1990) and ISSR (Akagi et al., 1996; Gupta et al., 1994; Ratnaparkhe et al., 1998; Sankar and Moore, 2001; Tsumura et al., 1996; Wang et al., 1998; Wu et al., 1994; Zietkiewicz et al., 1994) techniques bring some important advantages. They have a wide range of applications in various types of studies and, taking into consideration their versatility, they are applicable to the problems defined in the aim of the present study.

Analysis of a methodological aspect of the presented research results shows they are in accordance with the results of research on other plant species that used the aforementioned techniques for similar research objectives (Akagi et al., 1996; Lanham et al., 1995; Levi and Rowland, 1997; Moreno et al., 1995; Sankar and Moore, 2001; Wang et al., 1998; Wu et al., 1994).

A set of over twenty primers of known origin was used for both RAPD and ISSR technique. As a result of the amplifications, for the examined Aronia genotypes 845 (RAPD) and 772 (ISSR) reaction products were generated with the amplification of 214 (RAPD) and 184 (ISSR) loci, and the length of the amplified RAPD products $(2810-270 \mathrm{bp})$ or ISSR products (3060-260 bp) corresponded to the number of products amplified, the number of primers used, and length of products generally generated by these methods (Williams et al., 1990, Zietkiewicz et al., 1994).

The above-mentioned methodological correctness of the used methods and, above all, reliability of the obtained results were validated by the anal- ysis of correlations between the genetic similarity matrices calculated for RAPD and ISSR fingerprints of the examined Aronia genotypes. A significant correlation coefficient $(\mathrm{r}(\mathrm{AB})=0.531$, $\mathrm{p}$-value $=0.044$, $\mathrm{p}=0.05)$ calculated using the Mantel test confirmed that the diversity between the Aronia accessions, assessed with the use of the RAPD technique, is similar to that determined with the ISSR technique.

In both methods, the cultivar 'Hugin' was significantly different from the other accessions, while the others generally did not vary among themselves. The cultivar 'Hugin' is a Swedish tetraploid Aronia variety (Aronia melanocarpa (Marshall) Rehder) which may owe its genetic distinction to the hybrid origin and apomictic seed production (Poplavskaya, 1995). In the present study, a range of additional polymorphic RAPD and/or ISSR products were amplified for the cultivar 'Hugin'. In the general analysis they had the nature of cultivar-specific loci that were scarcely amplified for the other cultivars. The differences in genetic profiles between the examined cultivars and the cultivar 'Hugin' may also result from its origin, as it was selected in Sweden from the breeding material brought from Walpone Island (Canada).

As opposed to 'Hugin', the cultivars 'Viking' (Finland) and 'Nero' (the Czech Republic) are examples of cultivars deriving from breeding materials of not well-known origin. Some authors classify them as cultivars deriving from the hybrid $A$. $\times$ prunifolia (A. arbutifolia and A. melanocarpa), while others state that they derive from $A$. melanocarpa. Taking that into consideration, it can be only assumed that these cultivars are of very similar origin (Persson Hovmalm et al., 2004).

Very approximate research results in comparison to the presented characterization of the cultivars 'Nero' and 'Viking' were obtained by Persson Hovmalm et al. (2004), who described cultivars and populations of Aronia from various collections and, among other things, confirmed lack of genotypic differences (RAPD) between the cultivars 'Nero' and 'Viking', found no significant genotypic differences among tetraploid Aronia populations and discovered such differences among diploid Aronia populations.

Other observations were made by Brand (2005). He found that seedling populations from tetraploid plants are visually identical to the female parent regardless of the ploidy of the pollen used. When the author used a diploid female parent, he got segregation within the population (segregation). Brand (2005) also found that triploid Aronia produces fertile seed, even though triploidy typically results in sterility. It is likely that polyploidy accessions of Aronia have evolved to produce seed through apomixis as a functional manner in which to reproduce.

Small differences were found between the genotypes 'Galicjanka 1' and 'Galicjanka 2'. It should be highlighted that the plants whose DNA was tested, named as above, derivative from the cultivar-'Galicjanka'. The only differ- 
ence is their origin. One of the reasons for including them in the research was to examine the genetic similarity of these genotypes of the same plant cultivar, obtained from two different collections. It has been found small genetic differences between them. Since we did not have the biological material of other genotypes of cultivar 'Galicjanka', generalization of the present results to the whole chokeberry nursery production is not justified. In spite of that, various disturbances may be quite frequent in nursery of orchard plants in the production and distribution of plant material (varieties) (Mazzalupo et al., 2010; Mitre et al., 2009).

In this case, an important problem is Aronia breeders' lack of access to diverse gene resources that would enable the breeders to increase the range of diversity of newlybred cultivars by varied crossings and selection (Jeppsson 1999; Strik et al., 2003; Sueiro et al., 2006).

\section{Conclusions}

The genus Aronia due to its biological properties is one of the most valuable species of cultivated plants. Because of its origin, Aronia is also a specific and quite closed group of plants, characterized by low genotypic diversity in the natural environment. In the present study, a very small range of genotypic diversity was found in the examined Aronia genotypes. The analysis of 214 RAPD loci and 184 ISSR loci, confirmed by a significant correlation between the similarity matrices, proved that the used research techniques were able to determine real genetic relationships between the examined genotypes. Significant distinction of the cultivar 'Hugin' was found, which may be a result of the origin of its parental components. For the other Aronia genotypes examined in the study, similar and relatively high genetic similarity was found with the use of both the RAPD and ISSR technique (Tab. 4). What is more, the results of the present study present the diversity of several Aronia genotypes only to a limited degree. Therefore, it is difficult to generalize the results to the whole genus Aronia.

\section{References}

Akagi H, Yokozeki Y, Inagaki A, Nakamura A, Fujimura T (1996). A codominant DNA marker closely linked to the rice nuclear restorer gene, Rf-1, identified with inter-SSR fingerprinting. Genome 39:1205-1209.

Ara D (2002). Schwarzfrüchtige Aronia: Gesund-und bald "in aller Munde"? Flüssiges Obst 10:653-658.

Benvenuti S, Pellati F, Melegari M, Bertelli D (2004). Polyphenols, anthocyanins, ascorbic acid, and radical scavenging activity of Rubus, Ribes and Aronia. J Food Sci 69(3):164-169.

Borissova P, Valcheva S (1994). Antiinflammantory effects of flavonoids in the natural juice of Aronia melanocarpa rutin and rutin-magnesium complex on an experimental model of inflammation induced by histamine and serotonin. Acta Physiol et Pharmacol Bulg 20(1):25-30.

Brand M (2005). Aronia: Native Shrubs With Untapped Potential. Arnoldia.

Buntjer JB (2001). PhylTool 1.32. (Phylogenetic Computer Tools). Laboratory of Plant Breeding Wageningen Agricultural University. The Netherlands.

Felsenstein J (1985). Confidence limits on phylogenesis: An approach using the bootstrap. Evolution 39:783-791.

Gąsiorowski K, Szyba B, Brokos B, Kołaczyńska M, JankowiakWłodarczyk A, Oszmniański J (1997). Antimutagenic activity of anthocyanins isolated from Aronia melanocarpa fruits. Cancer Lett 119:37-46.

Gupta M, Chyi YS, Romero-Severson J, Owen JL (1994). Amplification of DNA markers from evolutionarily diverse genomes using single primers of simple-sequence repeats. Theor Appl Genet 89:998-1006.

Hardin JW (1973). The enigmatic chokeberries (Aronia, Rosaceae). Bull Torrey Bot Club 100:178-184.

Hukkanen AT, Polonen SS, Karenlampi SO, Kokko HI (2006). Antioxidant capacity and phenolic content of sweet rowanberries. J Agric Food Chem 54:112-119.

Jeppsson N (1999). Evaluation of black chokeberry, Aronia melanocarpa, germplasm for production of natural food colourants. Acta Horticult484:193-198.

Jeppsson N (2000). The effect of cultivar and cracking on the fruit quality in black chokeberry (Aronia melanocaupa) and the hybrids between chokeberry and rowan (Soubzis). Gartenbauwissenschaft 65:93-98.

Kahkonen MP, Hopia AI, Heinonen M (2001). Berry phenolics and their antioxidant activity. J Agricult Food Chem 49(8):4076-4082.

Kask K (1987). Large-fruited black chokeberry (Aronia melanocarpa). Fruit Varieties J 41:47.

Klein-Lankhorst RM, Vermunt A, Weide RT, Liharska, Zabel P (1991). Isolation of molecular markers for tomato ( $L$. esculentum) using random amplified polymorphic DNA (RAPD). Theor Appl Genet 83:108-114.

Kulling SE, Rawel HM (2008). Chokeberry (Aronia melanocarpa)-A review on the cCharacteristic components and potential health effects. Planta Med 74:1625-1634.

Lanham PG, Brennan RM, Hackett C, McNicol RJ (1995). RAPD fingerprinting of blackurrant cultivars (Ribes nigrum L.) cultivars. Theor Appl Genet 90:166-172.

Levi A, Rowland IJ (1997). Identifying blueberry cultivars and evaluating their genetic relationships using randomly amplified polymorphic DNA (RAPD) and simple sequence repeats (SSR) anchored primers. J Amer Soc Hort Sci 122:74-78.

Lüdders P, Foltan H (1997). Einflüsse der N-Ernährung auf Wachstum, Ertrag und Anthocyangehalt von Aronia melanocarpa bei unterschiedlichem Fruchtbehang in 1 
284

Internationale Wildfruchttagung, Berlin Schrieftenreihe des Fachgebietes Obstbau, 97-100 p.

Manly BJF (1997). Randomization, Bootstrap and Monte Carlo Methods in Biology (Second Edition). London: Chapman and Hall.

Mitre I, Lukacs L, Ardelean M, Mitre V, Sestras R, Pop R, Cordea M (2009). Genotypic variability of the main apple cultivars grown in Transylvania, Romania, evaluated by means of RAPD Analysis. Not Bot Horti Agrobo 37(1):261264.

Moreno S, Gogorcena Y, Ortiz JM (1995). The use of RAPD markers for identification of cultivated grapevine (Vitis vinifera L.). Sci Hortic 62:237-243.

Mazzalupo I, Chiappetta A, Benincasa C, Perri E (2010). Intracultivar variability of three major olive cultivars grown in different areas of central-southern Italy and studied using microsatellite markers. Sci Hortic 126:324-329.

Nei M, Li WH (1979). Mathematical model for studying genetic variation in terms of restriction endonucleases. Proc Nat Acad Sci USA 76:5269-5273.

Oszmiański J, Sapis JC (1988). Anthocyanins in the fruits of Aronia melanocarpa (black chokeberry). J Food Sci 53:12411242.

Persson Hovmalm HA, Jeppsson N, Bartish IV, Nybom H (2004).RAPD analysis of diploid and tetraploid populations of Aronia points to different reproductive strategies within the genus. Hereditas 141:301-312.

Plocharski W, Zbroszczyk J (1989). Aronia fruit (Aronia melanocarpa Elliot) as a natural source of anthocyanin colourants. 1. Recovery of anthocyanins from aronia fruit by using alcoholic extraction. Fruit Sci Rep 16:33-39.

Poplavskaya TK (1995). Aronia, its economic significance and current status. In: A program and methods of breeding fruit, small-fruit and nut bearing crops. Oryol, Russia, 457-459 p.

Ratnaparkhe MB, Santra DK, Tullu A, Muehlbauer FJ (1998). Inheritance of inter-simple sequence repeat polymorphisms and linkage with a Fusarium wilt resistance gene in chickpea. Theor Appl Genet 96:348-353.

Richter G (1988). Stoffwechselphysiologie der Pflanzen. Physiologie und Biochemie des Primär- und Sekundärestoffwechsels. Stuttgart, Georg Thieme Verlag Stuttgart, 402-427 p.

Sankar AA, Moore GA (2001). Evaluation of inter-simple sequence repeat analysis for mapping in citrus and extension of genetic linkage map. Theor Appl Genet 102:206-214.

Simeonov SB, Botushanov NP, Karahanian EB, Pavlova MB, Husianitis HK, Troev DM (2002). Effects of Aronia melanocarpa juice as part of the dietary regimen in patients with diabetes mellitus. Folia Med (Plovdiv) 44(3):20-30.
Skupień K, Oszmiański J (2007). The effect of mineral fertilization on nutritive value and biological activity of chokeberry fruit. Agricult Food Sci (16)1:46-55.

Skvortsov AK, Maitulina YK (1982). On the differences between the cultivated chokebeny and its wild progenitors. Bulletin of the Central Botanical Gardens, Moscow. Nauke Publishers 126:35-40.

Strigl AW, Leitner E, Pfannhauser W (1995). Die schwarze Apfelbeere (Aronia melanocarpa) als natürliche Farbstoffquelle. Dtsch Lebensmitt Rundsch 91:177-180.

Strik B, Finn C, Wrolstad R (2003). Performance of chokeberry (Aronia melanocarpa) in Oregon, USA. Acta Horticult 626:439-443.

Sueiro L, Yousef GG, Seigler D, De Mejia EG, Grace MH, Lila MA (2006). Chemopreventive potencial of flavonoid extracts from plantationbred and wild Aronia melanocarpa (black chokeberry) fruits. J Food Sci 71:480-488.

Tanaka T, Tanaka A (2001). Chemical components and characteristics of black chokeberry. J Jpn Soc Food Sci Technol 48:606-610.

Tsumura Y, Ohba K, Strauss SH (1996). Diversity and inheritance of inter-simple sequence repeat polymorphisms in Douglas-fir (Pseudotsuga menziesii) and sugi (Cryptomeria japonica). Theor Appl Genet 92:40-45.

Vachleva-Kuzmanova S, Kuzmanov K, Tsanova-Savova S, Mihova V, Krasnaliev I, Borisova P (2007). Lipid-lowering effects of Aronia melanocarpa fruit juice in rats fed cholesterol-containing diets. J Food Biochem 31:589-602.

Van de Peer Y, De Wachter R (1994). TREECON for Windows: a software package 390 for the construction and drawing of evolutionary trees for the Microsoft Windows 391 environment. Computer App Bios 10: 569-570.

Wang G, Mahalingan R, Knap HT (1998). (C-A) and (G-A) anchored simple sequence repeats (ASSRs) generated polymorphism in soybean. Theor Appl Genet 96:1086-1096.

Williams JGK, Kubelik AR, Livak KJ, Rafalski JA, Tingey SV (1990). DNA polymorphisms amplified by arbitrary primers are useful as genetic markers. Nucleic Acids Res 18:6531-6535.

Wu KS, Jonas R, Dauneberger L, Scolnik BA (1994). Detection of microsatellite polymorphism without cloning. Nucleic Acids Res 22:3257-3258.

Zietkiewicz E, Rafalski A, Labuda D (1994). Genome fingerprinting by simple sequence repeat (SSR)-anchored polymerase chain reaction amplification. Genomics 20:176183. 